7. Reprod. Fert. (1973) 34, 451-456

\title{
CYTOTOXIC ACTION OF A MIXED COPOLYMER OF PHENYLMETHYLCYCLOSILOXANE ON RABBIT BLASTOCYST LYSOSOMES
}

\author{
R. ABRAHAM, J. C. FULFS, L. GOLBERG AND F. COULSTON \\ Institute of Experimental Pathology and Toxicology, \\ Albany Medical College, Albany, New York 12208, U.S.A.
}

(Received 31st fuly 1972)

\begin{abstract}
Summary. Administration of a mixed copolymer of phenylmethylcyclosiloxane to rabbits on Days 4 and 5 of pregnancy prevented implantation. Cytochemical and ultrastructural studies revealed that the macromolecular material was taken up by 6-day-old trophoblasts (but not the embryonic cells) and was sequestrated in vacuoles. The presence of acid phosphatase in some of these vacuoles identified them as belonging to the lysosomal system. Uptake into lysosomes of macromolecular material brings about degenerative changes in the trophoblast, impeding successful implantation. No evidence was observed of the changes in uterine cells that normally accompany implantation, nor was any siloxane-like material seen in lysosomes in the uterine epithelial cells or macrophages.
\end{abstract}

\section{INTRODUCTION}

The effects on reproduction of an equilibrated copolymer of mixed cyclosiloxanes, represented as cyclic $\left[(\mathrm{PhMeSiO})_{x}\left(\mathrm{Me}_{2} \mathrm{SiO}\right)_{y}\right]$ where $x+y=3$ to 8 and $\mathrm{Ph}$ is phenyl and $\mathrm{Me}$ is methyl (Bennett, Gorzinski \& LeBeau, 1972), have been studied. This macromolecular material (designated as PMxMMy) has been shown to interrupt the normal oestrous cycle in female rats, and to prevent implantation when administered to pregnant rats and rabbits (LeFevre, Coulston \& Golberg, 1972). In an attempt to investigate the mechanism by which the siloxane produced its effect on implantation, the lysosomal system was studied in order to ascertain whether these intracellular organelles were involved in the uptake of the macromolecular material.

The part played by lysosomes in the process of implantation, particularly in the trophoblast-uterus interaction, is not fully understood. Christie (1967) suggested that epithelial cells are removed by phagocytic activity of the syncytiotrophoblast. Enders \& Schlaf ke (1971) envisaged some phagocytic activity by the trophoblast in the early stages of implantation. The observations of Christie (1967) were made solely by histochemical techniques at the light microscopic level, while Enders \& Schlafke (1971) based their interpretations on electronmicroscopy that did not include a study of lysosomal enzymes. In a 
study of the sequence of events taking place during early nidation in the rabbit (Abraham, Hendy, Dougherty, Fulfs \& Golberg, 1970), no remarkable changes were found in the lysosomes of the blastocyst, and it seemed unlikely that the trophoblast was engaged in active phagocytosis during implantation. On the other hand, lysosomes of the uterine epithelial cells exhibited a series of striking structural transformations, involving the formation of autophagic vacuoles and residual bodies. It is reasonable to assume that these effects are associated with the degeneration and dissolution of the uterine cells.

Against this background of the events occurring in the course of normal nidation, the present study was undertaken to determine the effects of administration of PMxMMy on the lysosomes of the blastocyst and endometrium.

\section{MATERIALS AND METHODS}

Twelve female New Zealand rabbits, weighing 3.0 to $4.5 \mathrm{~kg}$, were used in this study. The copolymer of mixed cyclosiloxanes, PMxMMy, was supplied by the Dow Corning Corporation, Midland, Michigan. The material was dissolved in corn oil and doses corresponding to $100 \mathrm{mg} P M x M M y / k g$ were given by stomach tube on Days 4 and 5 of pregnancy, Day 0 being the day on which spermatozoa were found in the vaginal smear. Entire uterine horns with or without blastocysts were taken from rabbits killed by an overdose of pentobarbitone on Days 6, 8 and 10. Neither blastocysts nor embryos were recovered

\section{EXPLANATION OF PLATES 1 TO 4}

\section{PLATE 1}

FIG. 1 and 2. Light micrographs of rabbit blastocysts (6 days old) incubated for acid phosphatase activity by the technique of Gomori.

Fig. 1. 'Normal' blastocyst. Inner cell mass (ICM) and trophoblast $(T)$ are rich in lysosomes. $\times 140$.

Fig. 2. Blastocyst from a rabbit treated with PMxMMy. Note marked increase in lysosomal enzyme activity. Lysosomes appear large and intensely stained (arrow). × 140 .

\section{PLATE 2}

Fig. 3. Electronmicrograph of a 'normal' 6-day rabbit blastocyst, showing a nucleus $(\mathrm{N})$, mitochondria (M) and microvilli (V). $\times 6400$.

Fig. 4. Blastocyst from a rabbit treated with PMxMMy showing numerous vacuoles of different sizes, some containing amorphous material, presumably silicone (arrows). $\times 6300$.

\section{PLATE 3}

Fig. 5. Inner cell mass (ICM) and trophoblast (T) are illustrated in this electronmicrograph of a blastocyst from a rabbit treated with PMxMMy. Note that the vacuolation with siloxane-like material (arrows) is restricted to the trophoblast. $\times 1400$.

\section{PLATE 4}

Figures 6 to 8 illustrate material obtained from rabbits given PMxMMy, fixed and processed for acid phosphatase activity as described in the text.

Fig. 6. A 6-day-old blastocyst showing the distribution of acid phosphatase activity in various lysosomal structures (arrows), vacuoles of various sizes, and dense bodies. $\times 8200$. FIG. 7. High-power view of part of a blastocyst similar to that in Pl. 2, Fig. 4, but showing more clearly the nature of the macromolecular material. $\times 24,600$.

FIG. 8. High-power view demonstrating lysosomes containing dense material or crystalline structures. $\times 16,200$. 
PLATE 1

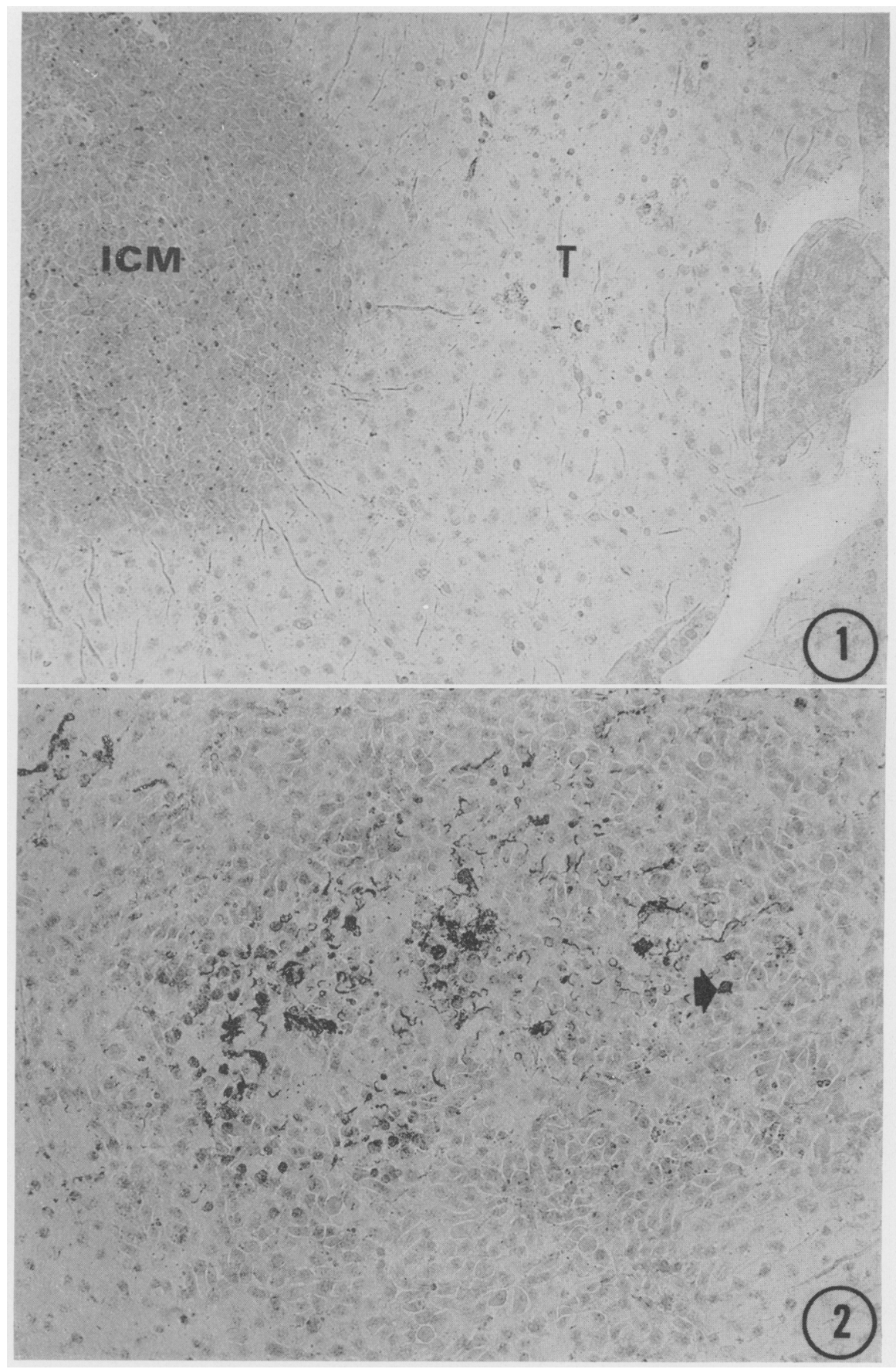

(Facing p. 452) 
PIAYE 2

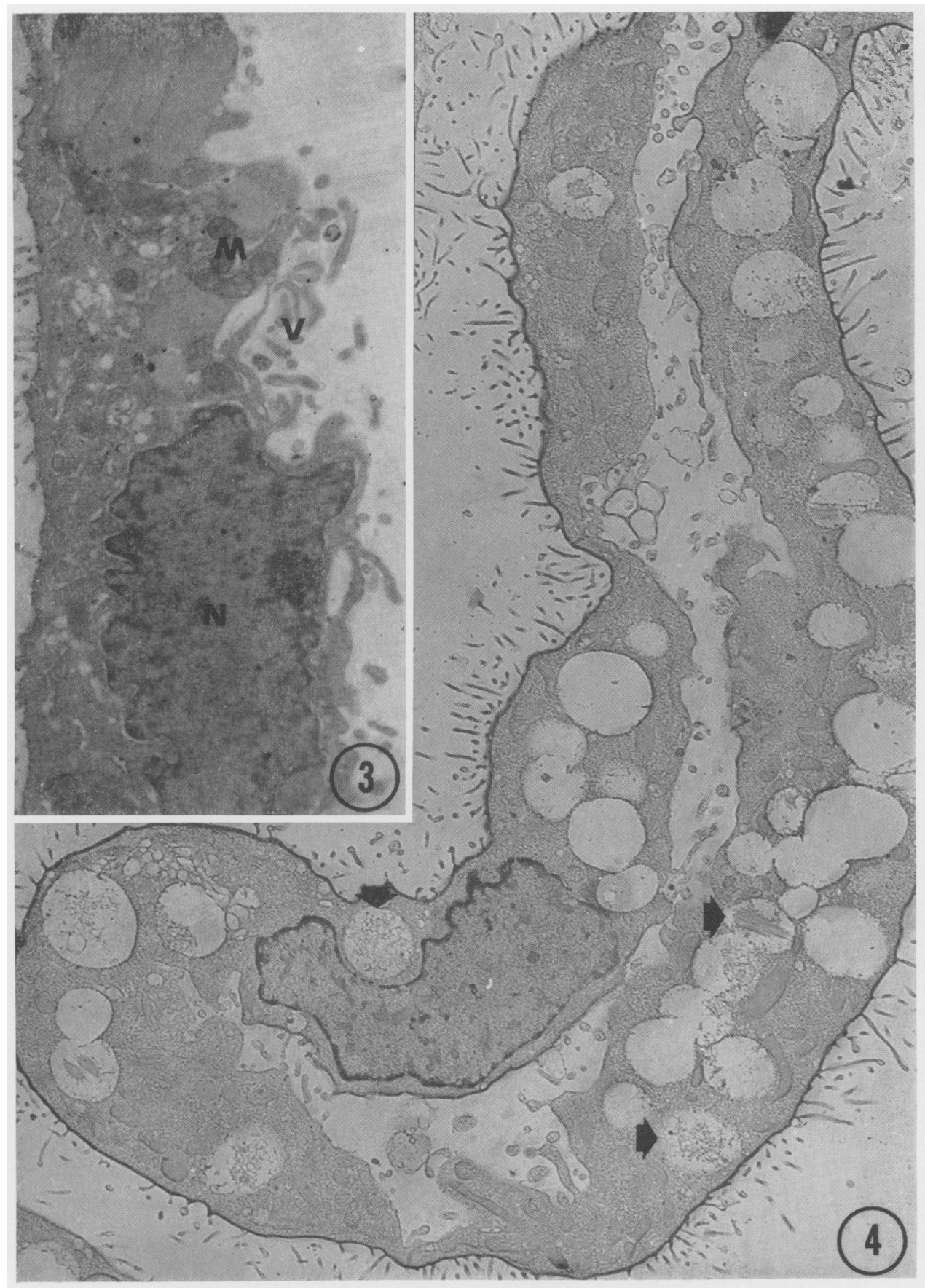


PI. IIL:3

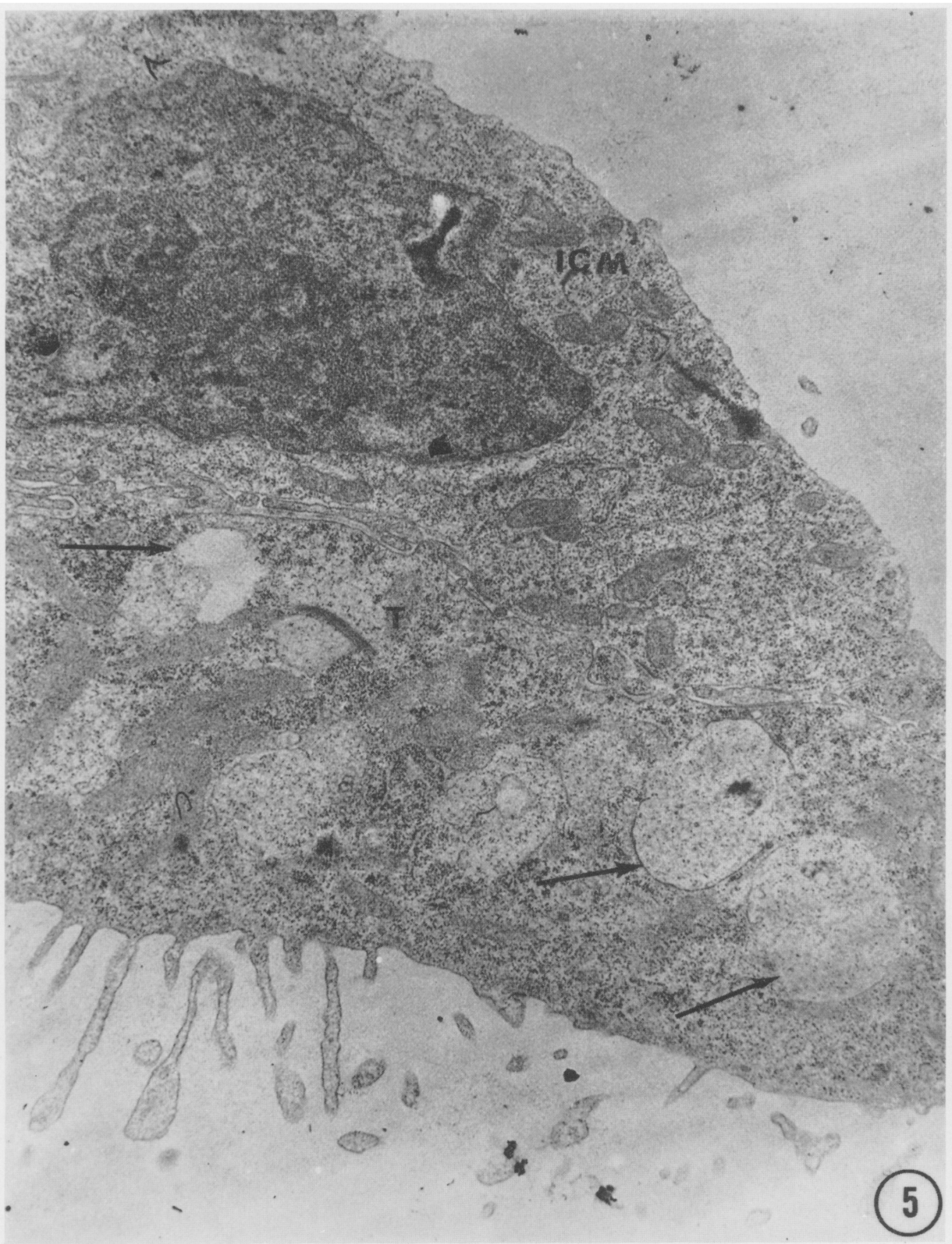



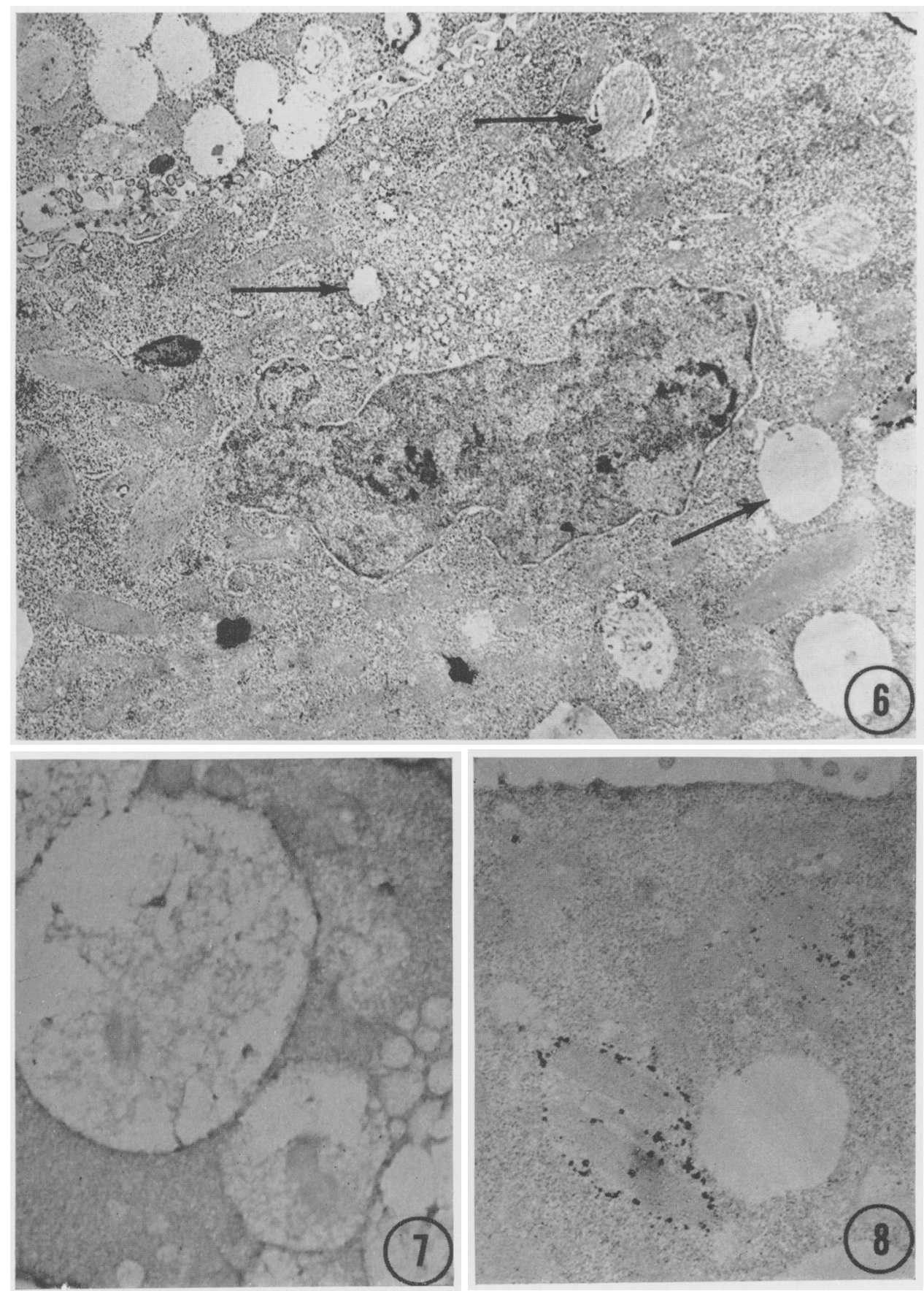

Facius $p .453\}$ 
on Days 8 and 10. Uterine tissue and blastocysts were also obtained from pregnant does not given PMxMMy. Blastocysts and uteri were fixed in formol calcium for 18 to $24 \mathrm{hr}$ and transferred to hypertonic gum sucrose (18 to $24 \mathrm{hr}$ ). Free-floating, frozen sections of uterus $8 \mu \mathrm{m}$ thick and whole, unsectioned blastocysts were stained for acid phosphatase by the methods of Gomori (1952) or Barka \& Anderson (1962). To demonstrate the presence of $\beta$-glucuronidase, the method of Hayashi, Nakajima \& Fishman (1964) was used. For electronmicroscopy, whole blastocysts and uterine sections $50 \mu \mathrm{m}$ thick obtained at various intervals of gestation were fixed either in formol calcium or glutaraldehyde and were stained by the method of Holt \& Hicks (1961). After incubation, the material was post-fixed for $1 \mathrm{hr}$ in osmium tetroxide, rapidly dehydrated in graded alcohols and embedded in Epon. Thin sections were cut on an MT2 ultramicrotome and examined with an RCA EMU-4 electronmicroscope.

\section{RESULTS}

\section{Light microscopy}

In blastocysts obtained from untreated does on Day 6 of gestation, acid phosphatase activity was limited to small granules present in the cytoplasm of both the trophoblast and the cells of the inner cell mass (Pl. 1, Fig. 1). Blastocysts derived from animals treated with PMxMMy displayed a noticeable increase in stained granules, some of which had coalesced to form large aggregates (Pl. 1, Fig. 2). Most of the aggregates were present in trophoblastic cells. Little $\beta$-glucuronidase activity was observed in control blastocysts; those recovered from treated does had more enzyme activity.

No distinction could be drawn with respect to the lysosomes in the uteri of treated and untreated does. In both cases, the lysosomes were located in perinuclear sites, indicating no change from the normal non-pregnant uterus.

\section{Electronmicroscopy}

The fine structure of the rabbit blastocyst has been adequately described by Enders (1971), and an illustration displaying the usual features associated with this cell type is provided in Pl. 2, Fig. 3. The most pronounced change evident after administration of PMxMMy to the doe was the presence of numerous vacuoles of different sizes. In some of the vacuoles, amorphous material was present (Pl. 2, Fig. 4 and Pl. 4, Fig. 7). Vacuolation was confined to trophoblastic cells only; no departure from normality was evident in embryonic cells (Pl. 3, Fig. 5).

When electron-cytochemistry of acid phosphatase activity was investigated, blastocysts from untreated does displayed few lysosomes. An increase in enzyme activity and in the number of lysosomes was a notable feature of blastocysts obtained from rabbits that had received PMxMMy. Secondary lysosomes of various sizes were observed, corresponding to the vacuoles described above; some of these contained acid phosphatase activity (Pl. 4, Fig. 6). An interesting finding was the presence of crystalline structures in lysosomes (PI. 4, Fig. 8).

Ultrastructural examination of the uteri from rabbits given PMxMMy confirmed that they had not undergone the usual changes in preparation for 
implantation. More specifically, the lysosomes were similar in their number and size to those seen in non-pregnant rabbits. There was no evidence of amorphous material in the epithelial cells or in the macrophages of the uterus. The cells and stroma of ovaries and oviducts were also free from any amorphous material.

\section{DISCUSSION}

Besides exhibiting antifertility effects in female rats and rabbits (LeFevre et al., 1972), PMxMMy produces an increase in uterine weight, increases in the height of the epithelial cells, proliferation of uterine glands and maturation of the muscle layers (Hayden \& Barlow, 1972). The similarity of changes in uterine histology induced by PMxMMy and by diethylstilboestrol were sufficiently striking for Hayden \& Barlow (1972) to conclude that PMxMMy acts through an oestrogenic mechanism.

Most of the work on the tissue distribution of siloxanes has involved study of the linear compounds, particularly dimethylpolysiloxane. Intraperitoneal or subcutaneous injection of this fluid leads to the accumulation of 'silicone-like' fluid in the reticulo-endothelial cells (RES) of the kidneys, spleen, liver, adrenals, ovaries, lymph nodes, pancreas, adipose tissue (Rees, Ballantyne, Seidman \& Hawthorne, 1967; Ben-Hur, Ballantyne, Rees \& Seidman, 1967) and erythrocytes (Hawthorne, Ballantyne, Rees \& Seidman, 1970).

The present study has demonstrated that amorphous material (presumably siloxane) is present in trophoblastic vacuoles that are membrane-bound and lysosomal in nature, as indicated by their acid phosphatase activity. Similar vacuoles with amorphous material were not seen in the lysosomes or in the cytoplasm of the uterine epithelial cells or macrophages. The lack of any apparent effect of siloxane on the uterine lysosomes is difficult to explain, as is the failure of the lysosomes to follow the usual sequence of changes involving the formation of autophagic vacuoles and residual bodies associated with degeneration of uterine epithelium in preparation for successful nidation. If the siloxane exerts an oestrogenic effect (Hayden \& Barlow, 1972), the uterus may be denied the requisite amount of hormone necessary for bringing about labilization of lysosomes (Abraham et al., 1970). On the other hand, the presence and attachment of a viable trophoblast may be necessary to stimulate the lysosomes towards autophagy. In this connection, it is pertinent to note that during their contractile movements, rat blastocysts are thought to release material contained in vesicles; this material is absorbed by the uterine epithelium and constitutes the stimulus for the endometrial response that makes successful implantation possible (Bitton-Casimiri, Brun \& Psychoyos, 1971). In the rabbit, these vesicles, whose exocytosis we have observed, contain acid phosphatase and are presumably lysosomal in nature (Abraham et al., 1970). Numerous vacuoles that readily absorbed horseradish peroxidase were noted by Enders \& Schlafke (1971) in trophoblastic knobs; the authors interpreted these structures as containing absorbed rather than secretory material. It must be mentioned, however, that lysosomes in a variety of cells take up exogenous horse-radish peroxidase.

Although the manner in which the siloxane finds its way into the uterine 
lumen is not clear, its presence in blastocyst lysosomes is an interesting finding. The inability of the fetal trophoblast to implant may then be related to the cytotoxic action of the siloxane-like material. The mechanism by which this cytotoxicity is brought about may be attributed to stimulation of the lysosomes and their contained enzymes by the macromolecular material, followed by the release of the hydrolases into the cytoplasm of the trophoblast, thus setting forth a process of disintegration and dissolution. Evidence of increased lysosomal activity is also provided by the presence of large numbers of autophagic vacuoles (crystalloid bodies in lysosomes). Hadek \& Swift (1960) observed crystalloid structures within the rabbit blastocyst which increase appreciably during the period of maximum protein synthesis, perhaps indicating that a majority of the protein is to be found in the crystalloids (Enders, 1971). These events may account for our inability to recover recognizably intact blastocysts on Days 8 and 10 of pregnancy. A further curious feature is the observation that the uptake of the macromolecular material by lysosomes is confined to the trophoblast. Absence of this material from the embryonic cells suggests that these cells have not been damaged, and that transfer of the blastocyst into a favourable environment might restore its viability. We are investigating this possibility by observing the growth of the blastocyst in vitro as well as its growth when introduced into untreated does. Siloxanes with a variety of different chemical structures are under active study. It is hoped that these results will form the basis of a new and practical approach to the prevention of blastocyst implantation.

\section{ACKNOWLEDGMENTS}

The authors are grateful to Mrs Margaret Colley, Mrs Veena Shaw and Mr Russell Mankes for assistance in histochemistry and electronmicroscopy. They are also grateful to Dr D. Bennett of the Dow Corning Corporation for the supply of PMxMMy.

This research was supported by Grant Number 5 P01 00266-5 from the National Institute of Environmental Health Sciences, NIH, USPHS and by the National Institutes of Health Training Grant 5 T01 ES 00102-5.

\section{REFERENCES}

Abraham, R., Hendy, R., Dougherty, W. J., Fulfs, J. G. \& Golberg, L. (1970) Participation of lysosomes in early implantation in the rabbit. Exp. E Molec. Path. 13, 329.

BARKa, T. \& Anderson, P. J. (1962) Histochemical methods for acid phosphatase using hexazonium pararosaniline as coupler. 7. Histochem. Cytochem. 10, 741.

Ben-Hur, N., Ballantyne, D. L., JR, Rees, T. D. \& Seidman, I. (1967) Local and systemic effects of dimethylpolysiloxane fluid in mice. Plastic reconstr. Surg. 39, 423.

Bennett, D. R., Gorzinski, S. J. \& LeBeAu, J. E. (1972) Structure-activity relationships of oral organosiloxanes on the male reproductive system. Toxic. appl. Pharmac. 21, 55.

Brtton-Casimiri, V., Brun, J. L. \& Psychoyos, A. (1971) Active release of material from rat blastocysts developing in vitro. F. Reprod. Fert. 27, 461.

GHRIstie, G. A. (1967) Histochemistry of implantation in the rabbit. Histochemie, 9, 13.

ENDERs, A. C. (1971) The fine structure of the blastocyst. In: The Biology of the Blastocyst, p. 71. Ed. R. J. Blandau. University of Chicago Press, Chicago and London.

Enders, A. C. \& Schlafke, S. (1971) Penetration of the uterine epithelium during implantation in the rabbit. Am. F. Anat. 132, 219. 
Gomori, G. (1952) Microscopic histochemistry: principles and practice. University of Chicago Press, Chicago. HADEK, R. \& SWIFT, H. (1960) A crystalloid inclusion in the rabbit blastocyst. F. biophys. biochem. Cytol. $8,836$.

Hawthorne, G. A., Ballantyne, D. L., Jr, Rees, T. D. \& Seidman, I. (1970) Hematological effects of dimethylpolysiloxane. Fnl reticuloendoth. Soc. 7, 587.

Hayashi, M., Nakajima, Y. \& Fishman (1964) The cytologic demonstration of $\beta$-glucuronidase employing naphthol AS BI glucuronide and hexazonium pararosaniline: a preliminary report. 7. Histochem. Cytochem. 12, 293.

HAYDEN, J. F. \& BARLOW, S. A. (1972) Structure-activity relationships of organosiloxanes and the female reproductive system. Toxic. appl. Pharmac. 21, 68.

HoLt, S. J. \& Hicks, R. M. (1961) The localisation of acid phosphatase in rat liver cells as revealed by combined cytochemical staining and electron microscopy. 7. biophys. biochem. Cytol. 11, 47.

LeFevre, R., Coulston, F. \& Golberg, L. (1972) Action of a copolymer of mixed phenylmethylcyclosiloxanes on reproduction in rats and rabbits. Toxic. appl. Pharmac. 21, 29.

Rees, T. D., Ballantyne, D. L., JR, Seidman, I. \& Hawthorne, G. A. (1967) Visceral response to subcutaneous and intraperitoneal injections of silicone in mice. Plastic reconstr. Surg. 39, 402. 